Research Article

\title{
Synthesis and Characterization of Magnetite-Alginate Nanoparticles for Enhancement of Nickel and Cobalt Ion Adsorption from Wastewater
}

\author{
Omnia A. A. El-Shamy $\mathbb{D}^{1},{ }^{1}$ Ragaa E. El-Azabawy, ${ }^{2,3}$ and Olfat. E. El-Azabawy ${ }^{1}$ \\ ${ }^{1}$ Egyptian Petroleum Research Institute, Nasr City, Cairo 11727, Egypt \\ ${ }^{2}$ Chemistry Department, Faculty of Science, Al-Azhar University (Girls), Nasr City, Cairo, Egypt \\ ${ }^{3}$ Chemistry Department, Faculty of Science and Art-Al Mandaq (Girls), Al-Baha University, Saudi Arabia
}

Correspondence should be addressed to Omnia A. A. El-Shamy; omniaelshamy@yahoo.com

Received 1 May 2019; Revised 29 June 2019; Accepted 18 July 2019; Published 16 September 2019

Guest Editor: Emad M. Masoud

Copyright (C) 2019 Omnia A. A. El-Shamy et al. This is an open access article distributed under the Creative Commons Attribution License, which permits unrestricted use, distribution, and reproduction in any medium, provided the original work is properly cited.

\begin{abstract}
Superparamagnetic magnetite-alginate nanoparticles (M-AlgNPs) were synthesized utilizing a coprecipitation method. Then, the prepared M-AlgNPs were characterized via Fourier transform infrared spectroscopy (FTIR) and X-ray diffraction spectroscopy (XRD) to affirm the formation and the crystallinity of this composite. In addition, the surface morphology of the prepared nanoparticles was inspected by transmission electron microscopy (TEM) which revealed well-dispersed nanoparticles of $\mathrm{Fe}_{3} \mathrm{O}_{4}$ into alginate. The adsorption characteristics of the synthesized nanoparticles for removing $\mathrm{Ni}^{+2}$ and $\mathrm{Co}^{+2}$ from wastewater were evaluated via atomic absorption measurements (AAS). The elimination efficiency of the MAlgNPs was detected at $\mathrm{pH}=7$ in $100 \mathrm{ppm}$ (initial concentration) of $\mathrm{Ni}^{+2}$ and $\mathrm{Co}^{+2}$, separately. The M-AlgNPs provided the maximum equilibrium uptake percentage for $\mathrm{Ni}^{+2}$ and $\mathrm{Co}^{+2}$ of 97.88 and $95.01 \%$, respectively. The adsorption of $\mathrm{Ni}^{+2}$ and $\mathrm{Co}^{+2}$ onto the M-AlgNP surface was found to fit the Langmuir model with $R^{2}$ values higher than that obtained from the Freundlich model for both metal ions. Moreover, $R_{L}$ "separating factor" for the adsorption process was assessed and found to be less than unity; this expresses the higher ability of the investigated metal ions to be adsorbed onto the M-AlgNP surface. The adsorption method was discovered to be $\mathrm{pH}$-dependent and well-suited to the isothermal equations of Langmuir and Freundlich. For regeneration studies, M-AlgNPs have been investigated and results confirmed that it could be reused with effective sorption capacity over three cycles.
\end{abstract}

\section{Introduction}

Water pollution with metal ions is an enormous ecological problem, as they damage even at small levels. Metal ions, for instance, nickel, cobalt, lead, and iron, are toxic and have nonbiodegradable characteristics that cause difficulty for both the earth and life. Removing these metal ions from the sewage stream is an important demand for a healthy setting. Several techniques have been used to eliminate metal ions from wastewater such as exchange of ions, extraction of solvents, flotation, oxidation, and adsorption [1-3]. Adsorption has gradually gained a lot of attention since late in perspective of the fact that this technique is essential and it generally has minimal effort and energy in expelling important metal particles from water.

Numerous sorts of adsorbents for treatment have been produced, for example, activated carbon, natural bentonite, tobacco stem ash, and calcium alginate beads [4-7]. As of late, with the quick advancement of nanotechnology, nanoparticles are at present concentrated. Generally, the research found that nanosorbents have great adsorption limits concerning metal ion elimination from water due to the large surface area and high reusability of these nanomaterials.

The adsorption technique combined with magnetic features for metal ion separation is utilized widely in wastewater remediation and green treatment, because of their little 
size and superparamagnetic properties. Also, these particles can be efficiently regained with an outer attractive field "magnet" and have a low threat effect.

Latterly, magnetic polymer nanoparticles got developing consideration in various fields because of their higher surface area and active sites to adsorb various pollutants. The magnetic polymer composite can be prepared via different methods; the most basic one is the independent preparation for the magnetic nanoparticles and polymer materials and after that blending them physically or chemically. Another technique to get the magnetic polymer composite depends on in situ precipitation of magnetic material within the polymer, where the magnetic particles are encompassed by a hydrophilic polymer shell $[8,9]$.

Alginate is an unbranched polymer formed by linear block copolymerization of d-mannuronic acid and 1guluronic acid, characterized by high hydrophilicity and is considered as an ecofriendly material, biocompatible, and biodegradable [10].

In this study, magnetite-alginate nanoparticles (MAlgNPs) were synthesized via the coprecipitation method. The structure of the prepared M-AlgNPs was expressed using FTIR and XRD. The morphology and particle size of the synthesized nanomaterial were detected using TEM. In addition, M-AlgNPs were applied as a green adsorbent for removing $\mathrm{Ni}^{+2}$ and $\mathrm{Co}^{+2}$ from wastewater. The effect of $\mathrm{pH}$ values and adsorbent doses was studied. Moreover, the adsorption isotherm and equilibria of $\mathrm{Ni}^{+2}$ and $\mathrm{Co}^{+2}$ adsorption onto M-AlgNPs were studied using both Langmuir and Freundlich models.

\section{Materials and Experiments}

2.1. Materials. $\mathrm{FeCl}_{3} \cdot 6 \mathrm{H}_{2} \mathrm{O}$ (iron(III) chloride hexahydrate), $\mathrm{FeCl}_{2} \cdot 4 \mathrm{H}_{2} \mathrm{O}$ (iron(II) chloride tetrahydrate), sodium hydroxide, nickel sulfate $\left(\mathrm{NiSO}_{4} \cdot 5 \mathrm{H}_{2} \mathrm{O}\right)$, and cobalt nitrate $\left(\mathrm{Co}\left(\mathrm{NO}_{3}\right)_{2}\right)$ are of analytical grade and are obtained from Merck, Germany. Sodium alginate was purchased, and Pluronic PE 6400 was from Sigma.

The fresh concentration of $\mathrm{Ni}^{+2}$ and $\mathrm{Co}^{+2}$ was prepared by means of adequate dilutions for the purchased solutions.

2.2. Synthesis of M-AlgNPs. M-AlgNPs were synthesized via the coprecipitation technique, where $\mathrm{FeCl}_{3} \cdot 6 \mathrm{H}_{2} \mathrm{O}$ and $\mathrm{FeCl}_{2} \cdot 4 \mathrm{H}_{2} \mathrm{O}$ have been dissolved separately in the ratio of $2: 1$. Then, the two previous solutions were mixed and heated $\left(65^{\circ} \mathrm{C}\right)$ under mild stirring using a mechanical stirrer. An aqueous solution of $\mathrm{NaOH}(3 \mathrm{M})$ is then added drop by drop until the formation of black suspended particles. The reaction continued for $30 \mathrm{~min}$ under the same conditions $[11,12]$. Then, magnetite alginate was prepared via a ionotropic gelation method. Firstly, the previously synthesized magnetite nanoparticles were redispersed in a solution $2.5 \%$ of sodium alginate using an ultrasonic bath for $5 \mathrm{~min}$. The resulting M-AlgNPs were washed several times with deionized water; then, the particles were magnetically separated.
2.3. Characterization of M-AlgNPs. FTIR was used to distinguish the functional groups of M-AlgNPs using FTIR1615 (Perkin Elmer (USA)) using the $\mathrm{KBr}$ disc, in wavenumbers that ranged from 4000 to $400 \mathrm{~cm}^{-1}$. The crystal structure of the synthesized M-AlgNPs was estimated via an X-ray diffraction technique (Panalytical X'Pert PRO MPD (Netherlands)). The instrument is outfitted with a copper anode $(\mathrm{Cu}-\mathrm{K} \alpha)$ producing wavelength radiation of $1.54 \AA$. The diffraction pattern was registered at ambient temperature in the angular width of $4-80(2 \theta)$ applying a scan time of $0.4(\mathrm{~s})$ and a step size of $0.02(2 \theta)$. Zeta potential values were measured (Malvern Zetasizer ZS-HT, United Kingdom) to detect the optimum $\mathrm{pH}$ for the adsorption process. The morphology of the prepared M-AlgNPs was viewed utilizing the transmission electron microscope, JEM 2100 (JEOL, Japan).

2.4. Adsorption Studies. The concentration of $\mathrm{Ni}^{+2}$ and $\mathrm{Co}^{+2}$ in the aqueous solution was determined using a ZEEnit 700P atomic absorption spectrometer (Analytik Jena, Germany) equipped with an air-acetylene and a slot burner of $100 \mathrm{~mm}$. The instrumental conditions were balanced by the producer's recommendations. The accuracy of measurement is accomplished through triple repetition for each concentration.

The batch experiments are used to detect the adsorption manner of the prepared $\mathrm{M}$-AlgNPs for $\mathrm{Ni}^{+2}$ and $\mathrm{Co}^{+2}$ (at room temperature). In this step, M-AlgNPs were added (known weight) to the metal ion aqueous solution separately and checked well $(200 \mathrm{rpm})$ for two hours (selected time). Then, the M-AlgNPs were separated by a magnet, and the remaining metal ion concentration is determined using FAAS.

The adsorption of $\mathrm{Ni}^{+2}$ and $\mathrm{Co}^{+2}$ onto the M-AlgNP surface was estimated in the $\mathrm{pH}$ range from 2 to 7.5 (using $0.1 \mathrm{M} \mathrm{NaOH}$ or $0.1 \mathrm{M} \mathrm{HNO}_{3}$ ). Moreover, the effect of the different weights of the synthesized M-AlgNPs was investigated at ambient temperature.

The capacity of adsorption at equilibrium $\left(q_{e}\right)$ is calculated in $\mathrm{mg} / \mathrm{g}$ using the following equation:

$$
q_{\mathrm{e}}=\frac{\left(C_{0}-C_{\mathrm{e}}\right) * V}{W},
$$

where $W$ is the weight of the synthesized M-AlgNPs (g), $V$ is the volume of the sample $(\mathrm{L}), C_{0}$ is the initial metal ion concentration $(\mathrm{mg} / \mathrm{L})$, and $C_{\mathrm{e}}$ is the concentration of the metal ions at equilibrium $(\mathrm{mg} / \mathrm{L})$.

\section{Results and Discussion}

The procedure of the coprecipitation reaction of formation of $\mathrm{Fe}_{3} \mathrm{O}_{4}$ can be summed up by the formation of oxygenated bridges between $\mathrm{Fe}(\mathrm{III})$ and $\mathrm{Fe}(\mathrm{II})$. Before the synthesis steps, the initial ratio of $\mathrm{Fe}(\mathrm{III})$ and $\mathrm{Fe}(\mathrm{II})$ is obtained as an acid solution to avoid the formation of hydroxide form before mixing. Then, the two ratios are mixed and dispersed well, and $\mathrm{NaOH}$ solution is added causing the precipitation of iron ions as hydroxide. The previously formed hydroxide 


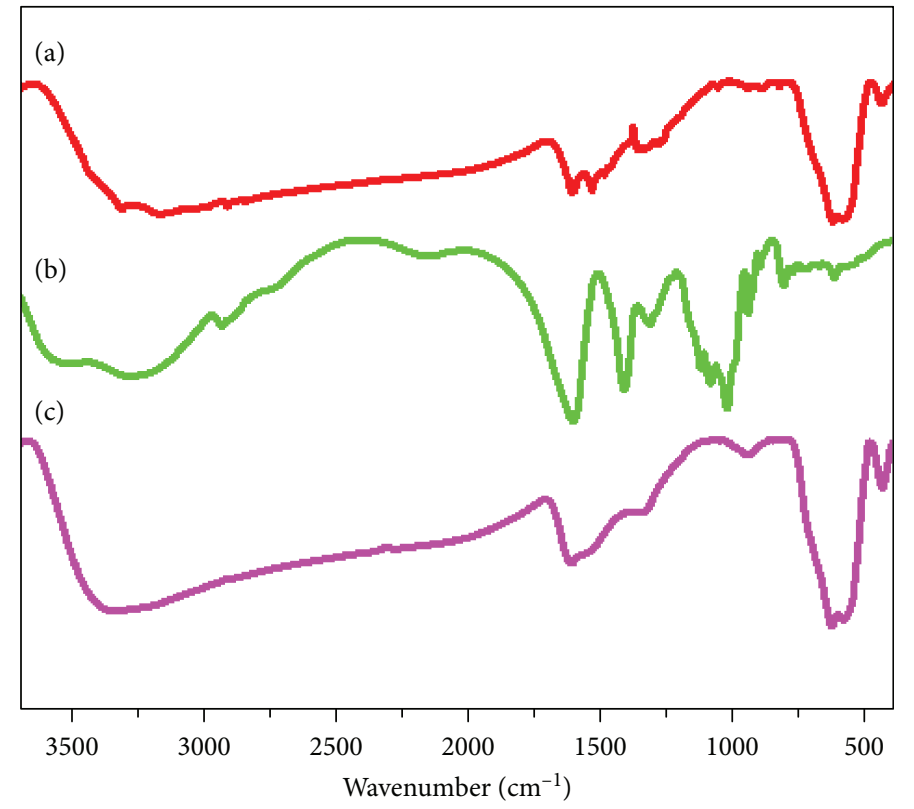

Figure 1: FTIR spectra of (a) $\mathrm{Fe}_{3} \mathrm{O}_{4}$ NPs, (b) sodium alginate, and (c) M-AlgNPs.

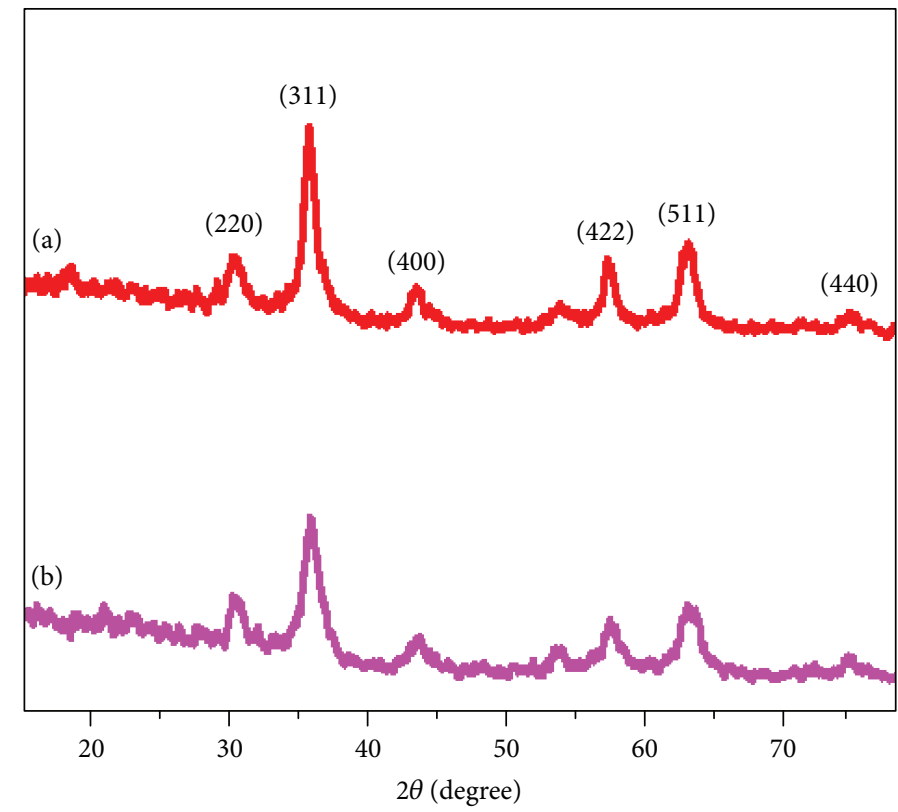

FIgURE 2: XRD pattern of (a) $\mathrm{Fe}_{3} \mathrm{O}_{4}$ nanoparticles and (b) M-AlgNPs.

precipitate is converted to the oxides through the formation of the oxygenated bridge $[11,13]$.

The reaction can be described by the following equation:

$$
2 \mathrm{Fe}^{+3}+\mathrm{Fe}^{+2}+8 \mathrm{OH}^{-} \rightarrow \mathrm{Fe}_{3} \mathrm{O}_{4}+4 \mathrm{H}_{2} \mathrm{O}
$$

3.1. Characterization of M-AlgNPs. Figure 1 shows the FTIR spectra of M-AlgNPs, which exhibit three peaks at 635,589 , and $441 \mathrm{~cm}^{-1}$ caused by the vibration of $\mathrm{FeO}$ bond in both octahedral and tetrahedral sites of the inverse spinel cubic of $\mathrm{Fe}_{3} \mathrm{O}_{4}$, respectively $[14,15]$. The peaks at 1623 and $1352 \mathrm{~cm}^{-1}$ were attributed to the stretching of the $\mathrm{C}=\mathrm{O}$ group in the alginate. In addition, the peak that appeared at $951 \mathrm{~cm}^{-1}$ was caused by the C$\mathrm{O}$ group. A broad band that ranged from 3200 to $3500 \mathrm{~cm}^{-1}$ is due to the $\mathrm{OH}$ group [16].

Figure 2 shows the spectrum of M-AlgNPs which is greatly matched to JCPDS file No. 19-0629. This confirms the formation of magnetite nanoparticles, as evidenced by the peaks at $2 \theta$ values of $30.33,35.79,43.65,57.35,62.99$, and $74.49^{\circ}$ that attributed to the crystal plan of magnetite at (220), (311), (400), (422), (511), and (440) (Figure 2). The presence of alginate is elucidated from the appearance of broad diffraction peaks at $2 \theta$ less than $20^{\circ}$ [17]. 


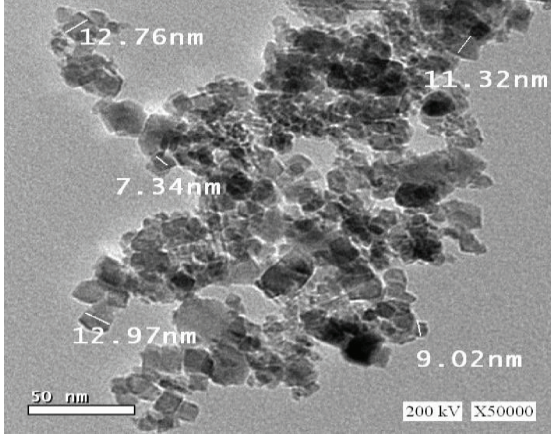

(a)

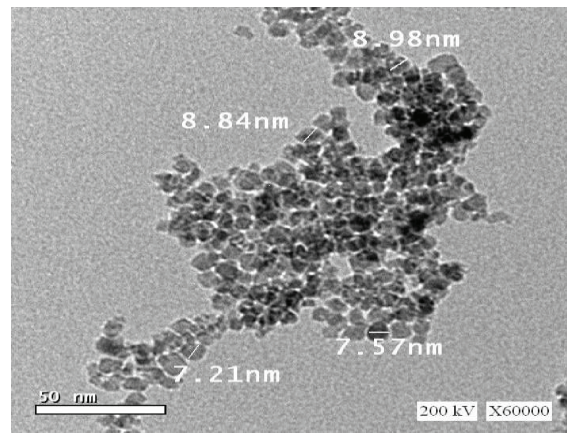

(b)

Figure 3: TEM images for (a) $\mathrm{Fe}_{3} \mathrm{O}_{4}$ NPs and (b) M-AlgNPs.

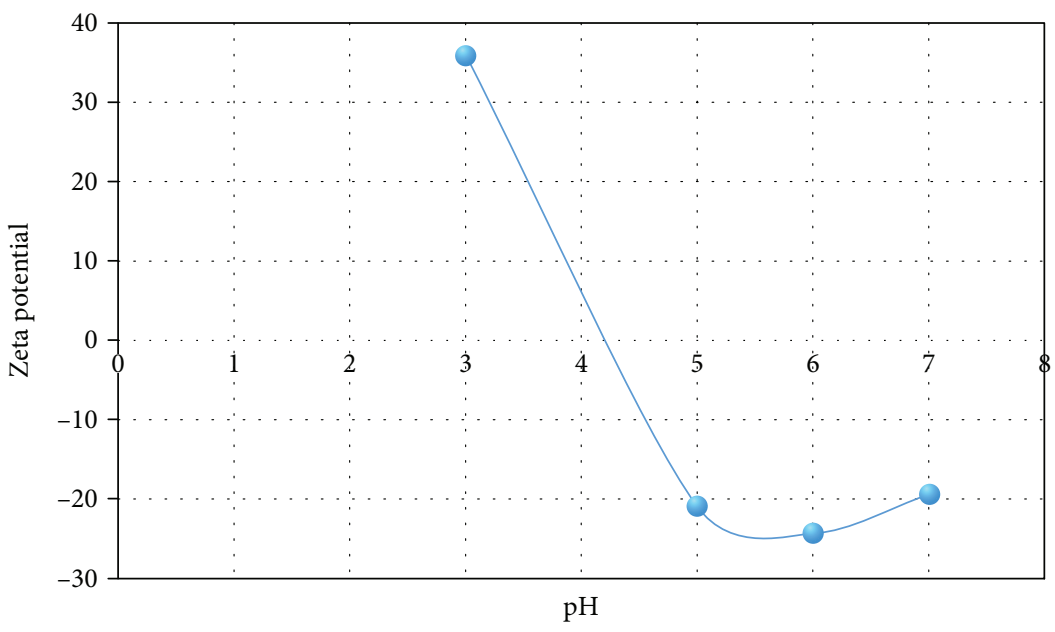

Figure 4: Zeta potential values of M-AlgNPs at different $\mathrm{pH}$.

The average particle size of M-AlgNPs can be assessed utilizing the Debye-Scherrer relation [18]:

$$
D=\frac{\kappa \lambda}{\beta \cos \theta} \text {, }
$$

where $D$ describes the mean diameter of M-AlgNPs, $\lambda$ is the wavelength of the radiation source, $\beta$ is FWHM (the full width at half-maximum) in radians, $k$ is constant, and $\theta$ is the half diffraction angle-Bragg angle.

According to the Debye-Scherrer equation, particle sizes of M-AlgNPs were estimated to be $9.22 \mathrm{~nm}$ with respect to the most intense peak (311).

Figure 3 shows that the synthesized M-AlgNPs are present as irregular spherical shape and have uniform size distribution with average diameters of around 7-9 $\mathrm{nm}$.

3.2. Adsorption Studies. It is outstanding that the $\mathrm{pH}$ values are a standout amongst the most essential elements that influence the manner of the adsorption process, since the $\mathrm{pH}$ of the metal ion solution controls the adsorption of these metals on the solid surfaces. Zeta potential measurement is determined for M-AlgNPs at different $\mathrm{pH}$ to detect the charge of the surface. Concerning Figure 4, the point of zero charge (isoelectric point) is found around 4.2. Above this point, the surface becomes negatively charged.

Experiments are performed to find the optimum $\mathrm{pH}$ on the adsorption of $\mathrm{Ni}^{+2}$ and $\mathrm{Co}^{+2}$ onto $\mathrm{M}$-AlgNPs using various $\mathrm{pH}$ values of 2 up to 7.5 ; above this $\mathrm{pH}$, the investigated metal ions begin to precipitate. Figure 5 shows the variation of the $\mathrm{pH}$ value on the adsorption behavior of $\mathrm{Ni}^{+2}$ and $\mathrm{Co}^{+2}$ onto M-AlgNPs using sorbent weight of $0.2 \mathrm{~g} / 100 \mathrm{~L}$ at $25^{\circ} \mathrm{C}$ and initial metal ion concentration of $100 \mathrm{mg} / \mathrm{L}$. The efficiency of adsorption was affected linearly by increasing the value of $\mathrm{pH}$ with the maximum value at $\mathrm{pH} 6.5$. From zeta potential and experimental results, the removal efficiency increases above the isoelectric point reaching maximum before the neutral ( $\mathrm{pH}$ 6.5) and higher negative value of zeta potential found around this $\mathrm{pH}$. Thus, the carboxylate groups at this $\mathrm{pH}($ zeta potential $=-24.3)$ have more negative charges leading to more attraction to the positively charged metal ions, while at the $\mathrm{pH}$ value of 2, the hydroxyl groups of alginate become protonated causing a decrease in the efficiency of the adsorption of $\mathrm{Ni}^{+2}$ and $\mathrm{Co}^{+2}$ onto M-AlgNPs $[19,20]$.

Different sorbent doses were used that ranged from 0.1 to $0.5 \mathrm{~g} / \mathrm{mL}$ for $100 \mathrm{mg} / \mathrm{L}$ metal ion concentration keeping other variables constant as shaking time, rpm, and temperature. 


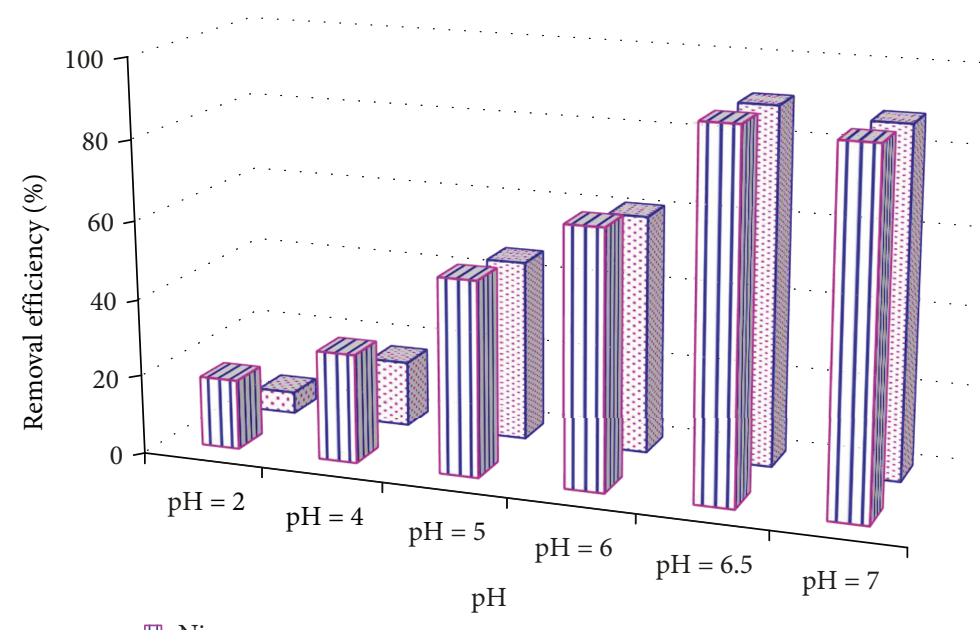

미 $\mathrm{Ni}$

응

FigURE 5: Effect of $\mathrm{pH}$ values on the removal percentage of heavy metal ions.

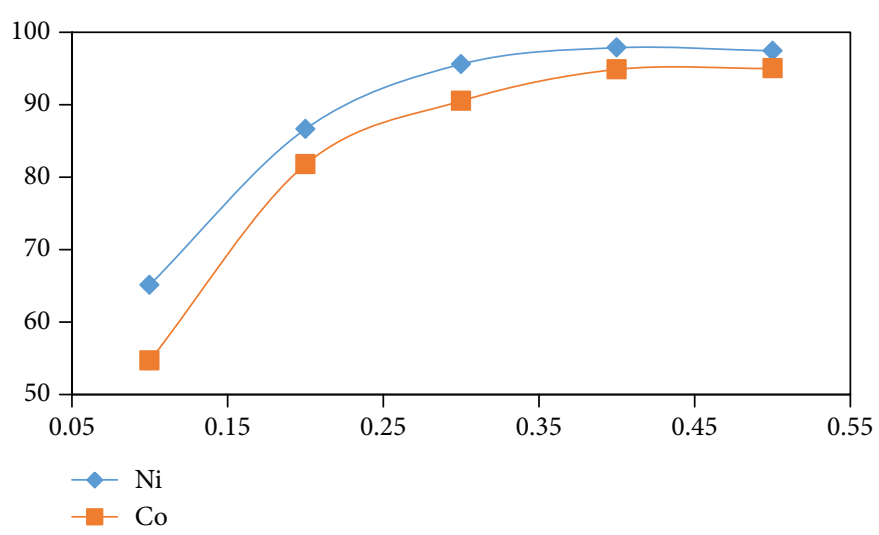

Figure 6: Effect of different weights from M-AlgNPs at $\mathrm{pH}$ of 6.5.

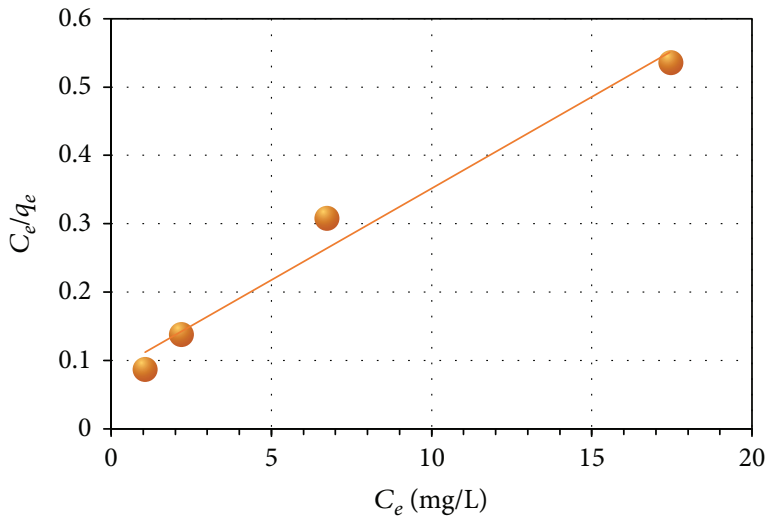

(a)

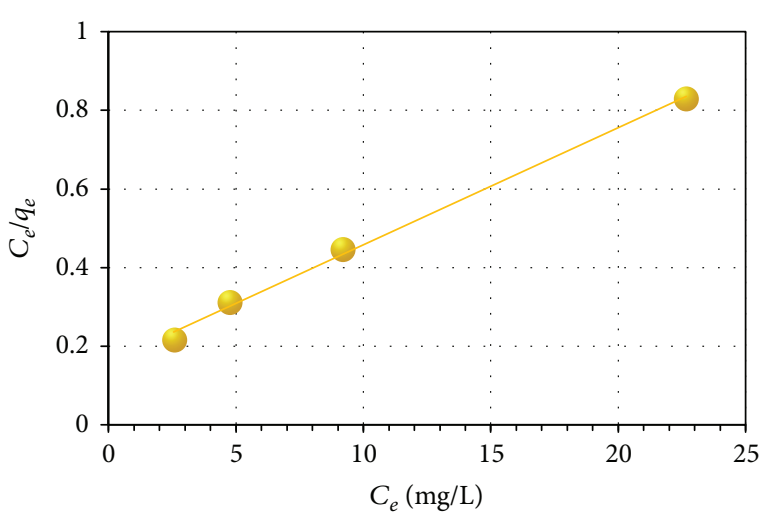

(b)

Figure 7: Langmuir isotherm for (a) Ni(II) and (b) Co(II) adsorbed at the prepared M-AlgNPs.

Figure 6 reveals that the elimination of $\mathrm{Ni}^{+2}$ and $\mathrm{Co}^{+2}$ increases with increasing the weight of M-AlgNPs. This is due to more available sites present with increasing the weight of adsorbent (M-AlgNPs) until $0.4 \mathrm{~g} / \mathrm{L}$. The decrease in the removal percentage with increasing the dose of the adsorbent surface is due to the repulsion between the large numbers of dispersed nanoparticles. So, the chance of metal ions to be attracted onto the MAlgNP surface decreases.

3.3. Adsorption Isotherms. The Langmuir isotherm describes the adsorption as the formation of one layer that covers the 
TABLE 1: Langmuir and Freundlich isotherm parameters for the adsorption of $\mathrm{Ni}(\mathrm{II})$ and $\mathrm{Co}(\mathrm{II})$ on the prepared M-ALgNPs.

\begin{tabular}{lccccc}
\hline \multirow{2}{*}{ Metal ions } & \multicolumn{2}{c}{ Langmuir } & \multicolumn{2}{c}{ Freundlich } \\
& $q_{\max }(\mathrm{mg} / \mathrm{g})$ & $b(\mathrm{~L} / \mathrm{mg})$ & $R_{f}$ & $\frac{1}{n}$ \\
\hline $\mathrm{Ni}(\mathrm{II})$ & 37.30 & 0.32 & 0.97 & 0.02 & 2.23 \\
$\mathrm{Co}(\mathrm{II})$ & 33.60 & 0.18 & 0.99 & 0.01 & 0.96 \\
\hline
\end{tabular}

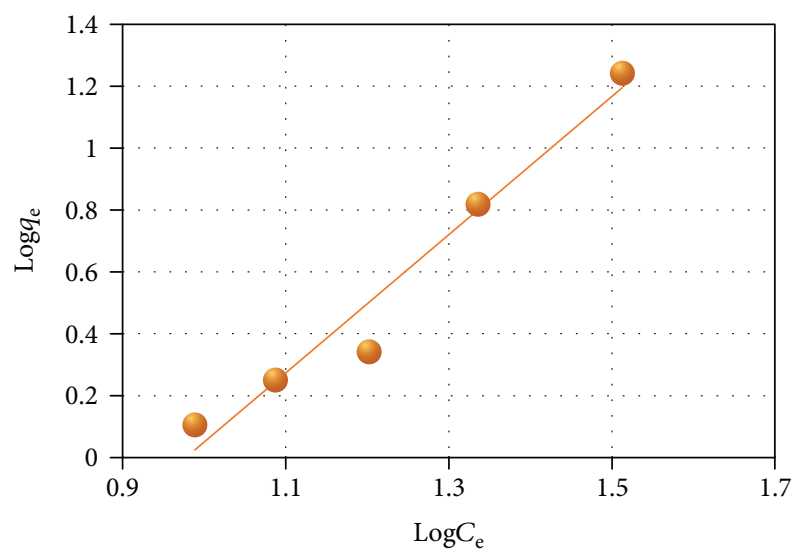

(a)

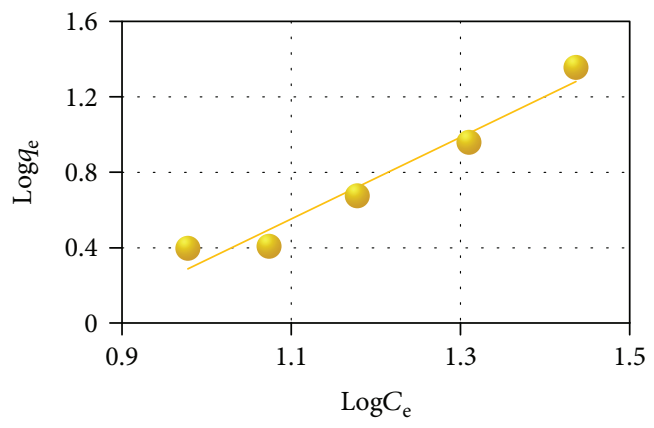

(b)

Figure 8: Freundlich isotherm for (a) Ni(II) and (b) $\mathrm{Co}(\mathrm{II})$ adsorbed at the prepared M-AlgNPs.

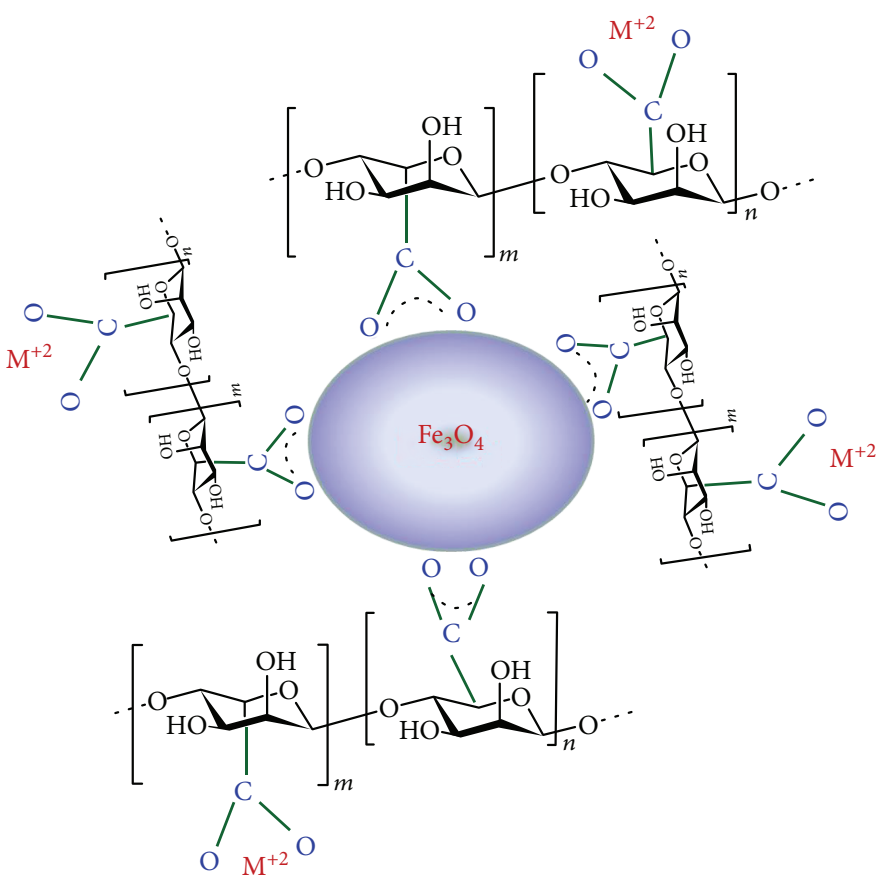

Scheme 1: The adsorption of metal ions on the M-AlgNPs.

sorbent surface and no further adsorption can occur [21], and it is represented by the following equation:

$$
\frac{C_{\mathrm{e}}}{q_{\mathrm{e}}}=\frac{1}{b q_{\max }}+\frac{C_{\mathrm{e}}}{q_{\max }},
$$

where $q_{\max }(\mathrm{mg} / \mathrm{g})$ is the maximum capacity of adsorption and $b(\mathrm{~L} / \mathrm{mg})$ is the Langmuir constant. Figure 7 shows the relation between $C_{\mathrm{e}} / q_{\mathrm{e}}$ and $C_{\mathrm{e}}$; the intercept and the slope facilitate the calculation of $b$ and $q_{\max }$, respectively. Table 1 represents the calculated adsorption parameters which confirm the obligation of the adsorption of $\mathrm{Co}^{+2}$ and $\mathrm{Ni}^{+2}$ onto the $\mathrm{M}$-AlgNP surface to the Langmuir relation.

Also, the following relation is applied for the Langmuir model to announce whether $\mathrm{Co}^{+2}$ and $\mathrm{Ni}^{+2}$ have a great 
affinity to be adsorbed on the M-AlgNP surface or not:

$$
R_{L}=\frac{1}{1+b C_{0}}
$$

where $R_{L}$ is the unit less constant called "separation factor," $b$ is the Langmuir constant, and $C_{0}$ is the initial concentration of polluted metal ions.

The values of $R_{L}$ have expressed the tendency of the pollutants to be adsorbed on the adsorbent surface. When the $R_{L}$ value exceeds unity, it indicates that there is no tendency for adsorption "undesirable." Meanwhile, the higher tendency of adsorption is achieved when the value of $R_{L}$ becomes more than zero and less than one. The calculated $R_{L}$ values for $\mathrm{Co}^{+2}$ and $\mathrm{Ni}^{+2}$ are 0.030 and 0.053 , respectively, indicating their higher tendency for adsorption onto M-AlgNPs.

Also, the adsorption manner can be described by the Freundlich isotherm model using the following equation:

$$
\log q_{\mathrm{e}}=\log K_{f}+\frac{1}{n} \log C_{\mathrm{e}}
$$

where $q_{\mathrm{e}}$ is the adsorption capacity at equilibrium $(\mathrm{mg} / \mathrm{g})$, $C_{e}$ is the concentration of each metal ions in the solution at equilibrium $(\mathrm{mg} / \mathrm{L}), K_{f}$ is the capacity of adsorption $\left(C_{0}=1\right)(\mathrm{mg} / \mathrm{g})$, and $n$ describes the intensity of the adsorption and is defined as the extent of reliance of the adsorption process with the concentration at equilibrium [22].

The Freundlich model states that the sorbent surfaces are heterogeneous and possess various binding energies. Figure 8 shows Freundlich adsorption isotherm, the values of $1 / n$ obtained from the slope and are observed to be more than unity, as shown in Table 1, which reveals the cooperative adsorption $[8,23]$. Langmuir isotherm gives higher $R^{2}$ values for adsorption of both metals than that obtained from Freundlich isotherm as listed in Table 1 indicating that metal ions are adsorbed as monolayer on the surface of M-AlgNPs.

The previous results suggest that $\mathrm{Co}^{+2}$ and $\mathrm{Ni}^{+2}$ are adsorbed on the prepared magnetite-alginate nanoparticle surface forming monolayer through the attraction between positive metal ion and outer oxygen atom as presented in Scheme 1. The prepared M-AlgNPs and the adsorbed metals are then separated using a strong magnet. Reusability of the M-AlgNPs as adsorbents for the metal ions was examined (under the same condition) due to financial and environmental concerns [24]. After the first adsorption process, the M-AlgNPs were tested again by stirring the adsorbent for 2 hours in 5 M HNO3 [25]. M-AlgNPs were carefully cleaned, separated with powerful magnets after adsorptiondesorption with deionized water, and then dried and reconditioned to the second cycle for adsorption. The findings indicate, for $\mathrm{Ni}^{+2}$ and $\mathrm{Co}^{+2}$, respectively, that the effectiveness of M-AlgNPs was 94.1 and $92.6 \%$ after being used three times.

\section{Conclusion}

Magnetite-alginate nanoparticles (M-AlgNPs) are synthesized, and the structure is characterized using FTIR and XRD measurements. Also, the morphology and the particle size were determined using TEM analysis. The prepared nanoparticles were applied as a green adsorbent for removing hazard metal ions "cobalt and nickel ions" as selected pollutants from an aqueous water sample separately. The efficiency of adsorption of $\mathrm{Co}^{+2}$ and $\mathrm{Ni}^{+2}$ onto the prepared M-AlgNP surfaces were 95.01 and $97.88 \%$, respectively. Moreover, the maximum capacity of adsorption $\left(q_{\max }\right)$ was 33.557 and $37.313 \mathrm{mg} / \mathrm{g}$ for $\mathrm{Co}^{+2}$ and $\mathrm{Ni}^{+2}$. Both Langmuir and Freundlich isotherm models were applied, and $R^{2}$ values were obtained and showed more fitting to Langmuir models for $\mathrm{Co}^{+2}$ and $\mathrm{Ni}^{+2}$. Additionally, the $R_{L}$ "separation factor" values are calculated depending on Langmuir models and confirming the higher ability of adsorption $1>R_{L}>0$.

\section{Data Availability}

All measurements are undergone in the Egyptian Petroleum Research Institute, and the condition is inserted inside the article. The authors are ready for any question.

\section{Conflicts of Interest}

The authors declare that there is no conflict of interests.

\section{References}

[1] A. Çimen, M. Torun, and A. Bilgiç, "Immobilization of 4amino-2-hydroxyacetophenone onto silica gel surface and sorption studies of $\mathrm{Cu}(\mathrm{II}), \mathrm{Ni}(\mathrm{II})$, and $\mathrm{Co}(\mathrm{II})$ ions," Desalination and Water Treatment, vol. 53, no. 8, pp. 2106-2116, 2013.

[2] E. A. El-Sharaky, M. R. Mishrif, and O. A. A. El-Shamy, "Synthesis and evaluation of a new trianionic surfactant for the removal of $\mathrm{Pb}$ (II) by flotation method," Tenside Surfactants Detergents, vol. 55, no. 2, pp. 148-152, 2018.

[3] M. N. Shalaby and O. A. A. El-Shamy, "Performance of some surfactants as wetting agents," Tenside Surfactants Detergents, vol. 42, no. 6, pp. 373-378, 2005.

[4] R. K. Ghosh and D. D. Reddy, "Tobacco stem ash as an adsorbent for removal of methylene blue from aqueous solution: equilibrium, kinetics, and mechanism of adsorption," Water, Air, \& Soil Pollution, vol. 224, no. 6, p. 1582, 2013.

[5] M. H. Kafshgari, M. Mansouri, M. Khorram, and S. R. Kashani, "Kinetic modeling: a predictive tool for the adsorption of zinc ions onto calcium alginate beads," International Journal of Industrial Chemistry, vol. 4, no. 1, p. 5, 2013.

[6] A. Kassale, K. Barouni, M. Bazzaoui, and A. Albourine, "Modification of wood by grafting of carboxylic acid functions using acrylic acid," Journal of Chemical, Biological and Physical Sciences, vol. 5, p. 2, 2015.

[7] Ş. Kubilay, R. Gürkan, A. Savran, and T. Şahan, "Removal of $\mathrm{Cu}$ (II), Zn (II) and Co (II) ions from aqueous solutions by adsorption onto natural bentonite," Adsorption, vol. 13, no. 1, pp. 41-51, 2007.

[8] A. M. Al-Sabagh, Y. M. Moustafa, A. Hamdy, H. M. Killa, R. T. M. Ghanem, and R. E. Morsi, "Preparation and characterization of sulfonated polystyrene/magnetite nanocomposites for organic dye adsorption," Egyptian Journal of Petroleum, vol. 27, no. 3, pp. 403-413, 2018.

[9] N. S. Rajurkar and D. Mahajan, "Adsorption of cobalt (II) and nickel (II) ions from aqueous solution on chitosan," vol. 6, pp. 1203-1217, 2016. 
[10] P. Aramwit, "Introduction to biomaterials for wound healing," in Wound Healing Biomaterials, pp. 3-38, Elsevier, 2016.

[11] D. Hritcu, M. I. Popa, N. POPA, V. Badescu, and V. Balan, "Preparation and characterization of magnetic chitosan nanospheres," Turkish Journal of Chemistry, vol. 33, pp. 785-796, 2009.

[12] N. M. Salem and A. M. Awwad, "A novel approach for synthesis magnetite nanoparticles at ambient temperature," Nanoscience and Nanotechnology, vol. 3, pp. 35-39, 2013.

[13] A. I. A. Sherlala, A. A. A. Raman, M. M. Bello, and A. Asghar, "A review of the applications of organo-functionalized magnetic graphene oxide nanocomposites for heavy metal adsorption," Chemosphere, vol. 193, pp. 1004-1017, 2018.

[14] K. Wu, S.-H. Liao, C.-H. Liu et al., "Functionalized magnetic iron oxide/alginate core-shell nanoparticles for targeting hyperthermia," International Journal of Nanomedicine, vol. 10, p. 3315, 2015.

[15] L. Yang, J. Tian, J. Meng et al., "Modification and characterization of $\mathrm{Fe} 3 \mathrm{O} 4$ nanoparticles for use in adsorption of alkaloids," Molecules, vol. 23, no. 3, p. 562, 2018.

[16] C. Li, J. Lu, S. Li, Y. Tong, and B. Ye, "Synthesis of magnetic microspheres with sodium alginate and activated carbon for removal of methylene blue," Materials, vol. 10, no. 1, p. 84, 2017.

[17] J. A. Lopez, F. González, F. A. Bonilla, G. Zambrano, and M. E. Gómez, "Synthesis and characterization of $\mathrm{Fe} 3 \mathrm{O} 4$ magnetic nanofluid," Revista Latinoamericana de Metalurgia y Materiales, vol. 30, pp. 60-66, 2010.

[18] M. Lee, X-Ray Diffraction for Materials Research: From Fundamentals to Applications, Apple Academic Press, 2016.

[19] M. R. Lasheen, I. Y. El-Sherif, M. E. Tawfik, S. T. El-Wakeel, and M. F. El-Shahat, "Preparation and adsorption properties of nano magnetite chitosan films for heavy metal ions from aqueous solution," Materials Research Bulletin, vol. 80, pp. 344-350, 2016.

[20] J. Shi, H. Li, H. Lu, and X. Zhao, "Use of carboxyl functional magnetite nanoparticles as potential sorbents for the removal of heavy metal ions from aqueous solution," Journal of Chemical \& Engineering Data, vol. 60, no. 7, pp. 20352041, 2015.

[21] A. A. El-Feky, M. N. Shalaby, and O. A. A. El-Shamy, "Polymers as hydrophobic adsorbent surface for some surfactants," Journal of Dispersion Science and Technology, vol. 30, no. 4, pp. 445-450, 2009.

[22] S. A. Elfeky, S. E. Mahmoud, and A. F. Youssef, "Applications of CTAB modified magnetic nanoparticles for removal of chromium (VI) from contaminated water," Journal of Advanced Research, vol. 8, no. 4, pp. 435-443, 2017.

[23] Department of Chemical Engineering, Faculty of Engineering, Chulalongkorn University, S. Puttamat, and V. Pavarajarn, "Adsorption study for removal of Mn (II) ion in aqueous solution by hydrated ferric (III) oxides," International Journal of Chemical Engineering and Applications, vol. 7, no. 4, pp. 239-243, 2016.

[24] E. M. El-Fawal and O. A. A. El-Shamy, "Photodegradation enhancement of 2-chlorophenol using ZnO-CdS@CS nanocomposite under visible light," International Journal of Environmental Science and Technology, pp. 1-12, 2019.

[25] M. R. Lasheen, I. Y. El-Sherif, D. Y. Sabry, S. T. El-Wakeel, and M. F. El-Shahat, "Removal and recovery of Cr (VI) by magnetite nanoparticles," Desalination and Water Treatment, vol. 52, pp. 6464-6473, 2014. 


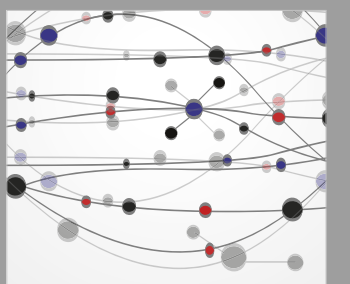

The Scientific World Journal
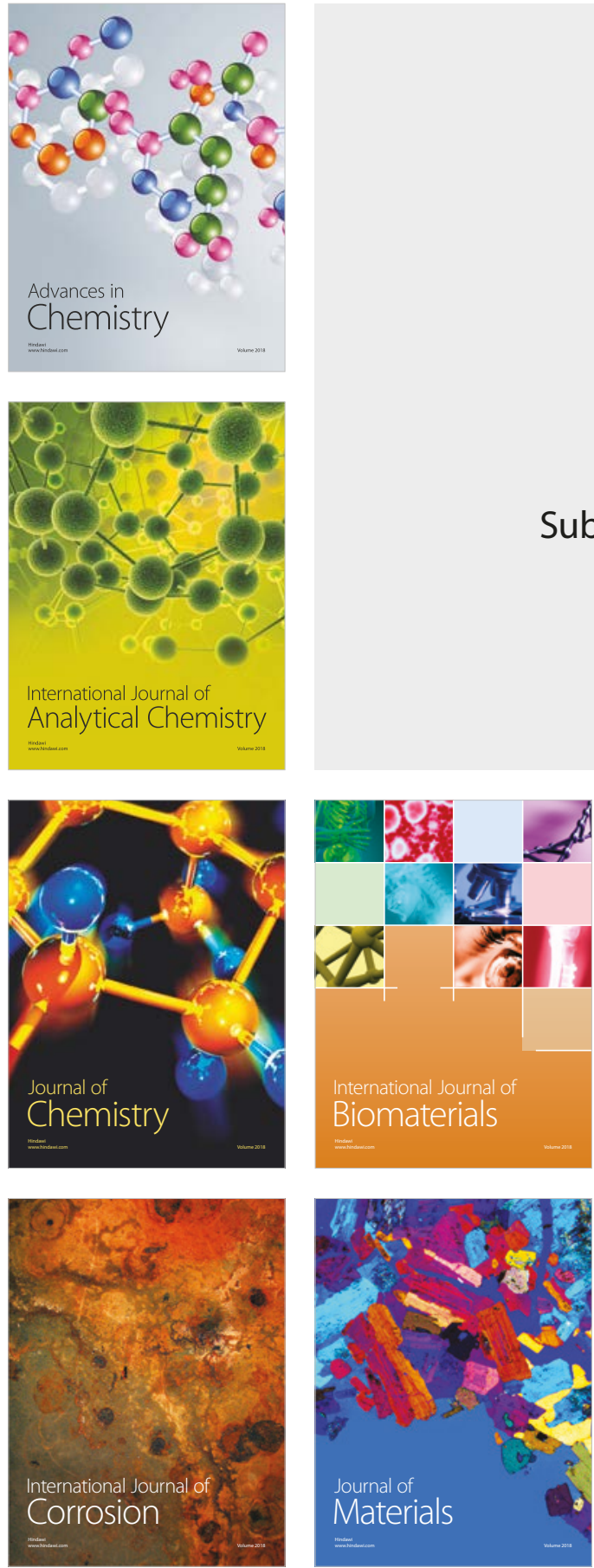

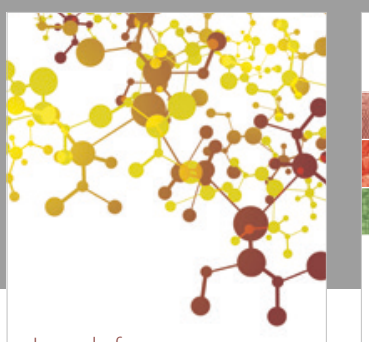

Journal of

Applied Chemistry
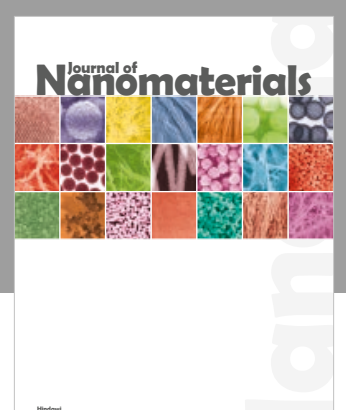

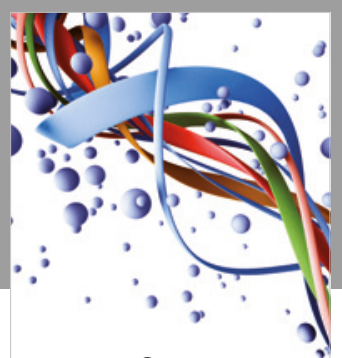

Scientifica

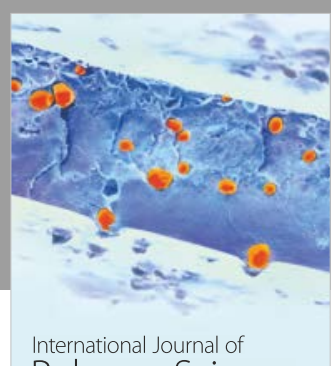

Polymer Science

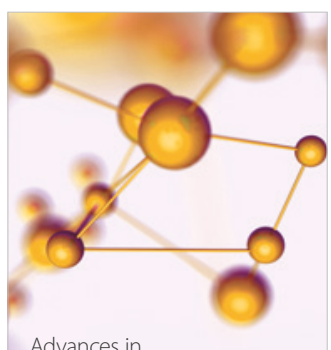

Physical Chemistry
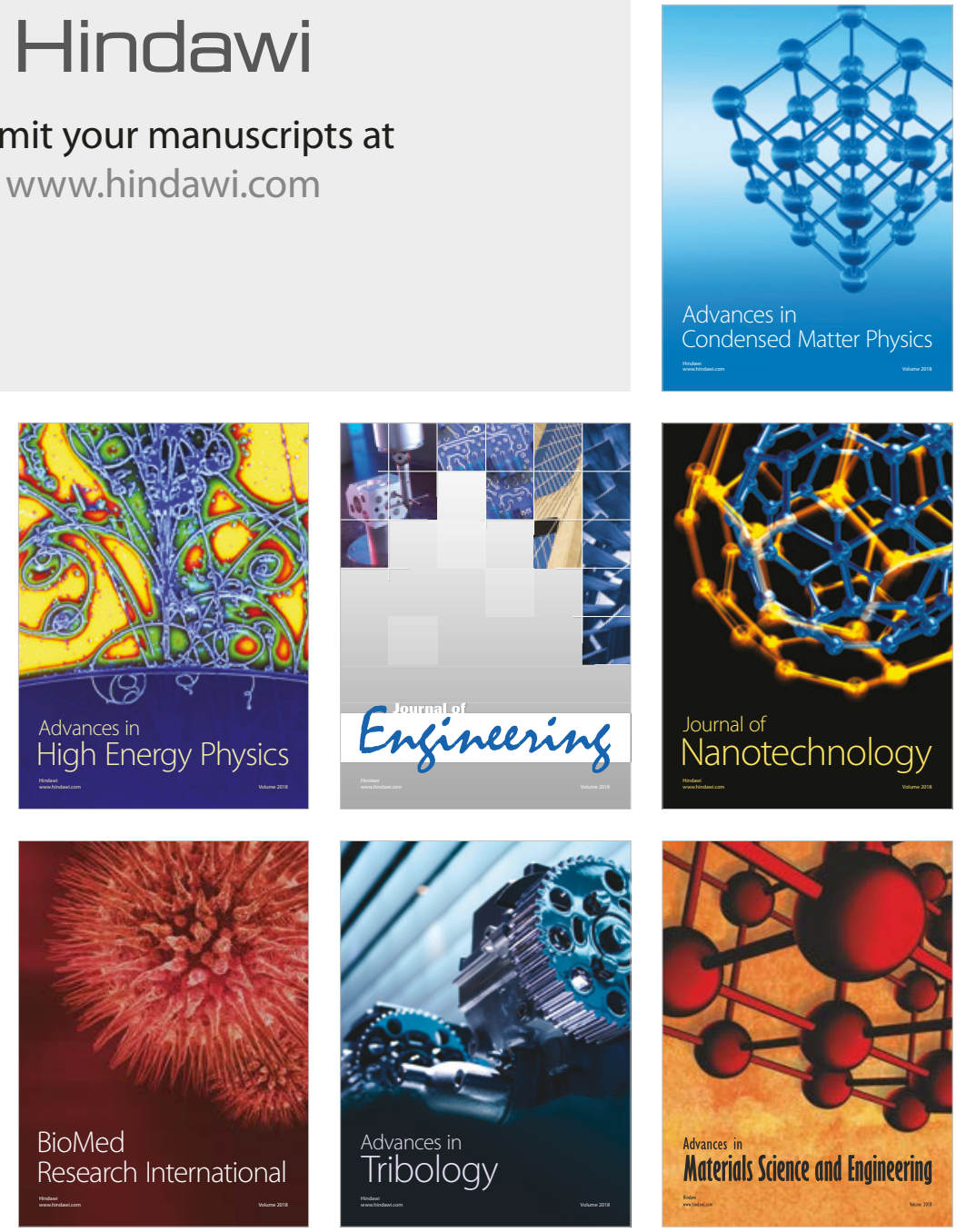